\title{
Comfort Improvement of a Novel Nonlinear Suspension for a Seat System Based on Field Measurements
}

\author{
Leilei Zhao - Changcheng Zhou* - Yuewei Yu \\ Shandong University of Technology, School of Transportation and Vehicle Engineering, China
}

This paper describes improved ride comfort of a novel nonlinear suspension for seat system based on field measurements. For the novel nonlinear suspension proposed, a rubber spring is used as its elastic element which has highly nonlinear characteristics to adapt various working conditions, and an asymmetrical damper is designed to yield asymmetric damping characteristics. Previous seat models were not very suitable for the system; thus, a nonlinear mathematical model was built to describe it better. Then, based on field measurements, the model parameters were identified, and the suspension damping coefficients were tuned under the practical constraints, to achieve satisfactory ride comfort to the greatest extent possible. Finally, the bench test was carried out, and the results show that, after the coefficients tuning, the seat vertical frequency-weighted root mean square (RMS) acceleration values are decreased by about $10 \%$ and $8 \%$ under the driving conditions on the highway and the gravel road, respectively, which proves the damping coefficients tuned are workable. The novel nonlinear suspension and the method of the damping coefficients tuning provide a valuable reference for further improving ride comfort to better protect the driver's health.

Keywords: ride quality; road conditions; nonlinear suspension; coefficients tuning

Highlights

- A rubber spring is used as an elastic element of seat suspension.

- A nonlinear mathematical model of seat suspension system.

- Integrated optimization of damping coefficients.

- Field measurements.

\section{O INTRODUCTION}

Seat suspension is an essential component of trucks. The design of seat suspension has significance for comfort improvement [1] to [3]. Prolonged exposure to occupational vibrations leads to some diseases for drivers [4] and [5]. Reducing the vibration transmitted from vehicle to the driver has become a key issue [6] and [7]. To reduce the vibration, various seat suspension systems use a wide variety of springs as the elastic component, including the coil spring, the air spring, and the rubber spring, etc.

Due to the good nonlinear characteristics of the rubber spring, it is widely used as the elastic element of vehicle suspension systems, especially in rail vehicle suspensions and in chassis suspensions of commercial vehicles. For example, to improve the service life of the rubber spring for rail vehicle suspensions, Luo et al. researched the fatigue design method of rubber springs [8]. Luo presented an evaluation method of the creep behaviours of the rubber suspension for railway vehicles [9]. Sebesan et al. analysed the broad application prospects of the rubber suspension on the railway vehicles [10]. Pang et al. analysed the mechanical properties of the rubber suspension for heavy vehicles using the finite element method [11]. Many research efforts on the modelling and designs of the vibration isolation system using rubber springs have been made. Thaijaroen and Harrison studied the dynamic behaviours of rubber isolators using a simulation model with six parameters [12]. Sun et al. investigated the modelling method and the parameter acquisition method of a rubber isolator [13]. In their paper [14], they presented a model to describe the hysteretic characteristics of a rubber isolator. Ren et al. studied the effects of the temperature and the pressure on the shear stiffness of the rubber spring [15].

In recent years, the rubber spring has been applied to the seat suspension. For example, Zhou et al. investigated a seat suspension system with a type of rubber spring embedded with metal splints [16]. The dynamic characteristics of the seat suspension should be matched according to the road conditions of vehicles [17] to [19]. The common methodology is to use a passive seat suspension system model to optimize the results, which could be approached by the single degree-of-freedom (DOF) vibration isolation system [20] and [21]. To facilitate the dynamic analysis of vehicles equipped with the rubber spring, Berg presented a rubber spring model with five parameters [22]. Shi and $\mathrm{Wu}$ presented a nonlinear model with fractional derivatives for rubber springs of railway vehicle suspensions [23]. 
These above studies about the designs of the vibration isolation system using rubber springs have significant relevance to the seat suspension. However, these previous models were not very suitable for the seat suspension system with a nonlinear hollow rubber spring and an asymmetrical damper with bushings, which will be optimized in this paper.

The objective of this work is to present a nonlinear mathematical model for a novel seat suspension system which employs a hollow rubber spring as the elastic element and improves its ride comfort by optimal design based on field measurements. According to the field measurements, the damping coefficients were tuned. In the end, by bench test, the optimal matching results were validated.

\section{SEAT SYSTEM MODEL}

The driver's seat analysed in this study is a new seat, which was tested for use in a heavy truck. The suspension seat was configured as a typical scissor system. It employs a hollow rubber spring and a hydraulic damper. They were mounted between the scissor structure on the seat pan and the seat frame. The hollow rubber spring, as shown in Fig. 1, is used as the elastic element of the seat suspension system, which has highly nonlinear characteristics to adapt the various working conditions.
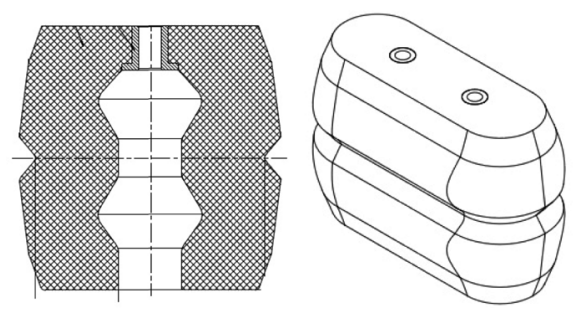

Fig. 1. The hollow rubber spring

A good and simple mathematical model would enable us to make reasonable indicative predictions of seat performance, and related models exist. The paper [25] provided a linear model of a seat suspension system with the damper mounting bushings. The paper [16] presented a nonlinear model of seat suspension system with the polynomial fitting the stiffness characteristics of the rubber spring, but the damper has linear damping. In this study, the seat dynamic properties are known to be non-linear, and the damper mounting bushings and friction in various seat components cannot be neglected, especially in response to low magnitude vibration. Thus, the previous models of seat suspension systems were not expected to be sufficient to simulate the driver's seat used in this study.

The assumptions made in formulating the model are as follows. Assumption 1: The elastic deformation of the seat frame could be ignored for this simplified model, and the driver is replaced by a matching block while removing the seat cushion. Assumption 2: The hollow rubber spring stiffness is considered to be nonlinear, while its damping is considered to be constant. Assumption 3: The asymmetric damping characteristics of the seat damper are simplified to be different constants in compression and rebound. Assumption 4: The Coulomb friction $F_{\mathrm{f}}$ within the linkage mechanism and the rubber spring is assumed to possess ideal properties. Assumption 5: The dynamic properties of the damper mounting bushings are characterized by equivalent linear stiffness while neglecting the damping coefficients.

A vertical dynamic model of the seat system was created on the basis of the assumptions, as shown in Fig. 2. $C_{\mathrm{s}}$ represents the rubber spring damping, $m$ represents the effective mass; $K_{\mathrm{b} 1}$ and $z_{\mathrm{b} 1}$ represent the upper bushing stiffness and vertical displacement, respectively; $K_{\mathrm{b} 2}$ and $z_{\mathrm{b} 2}$ represent the lower bushing stiffness and vertical displacement, respectively; $z_{\mathrm{S}}$ represents the seat pan vertical displacement; $q$ represents the vertical displacement input. Although the model is relatively simple, it can capture the major dynamic properties of seat suspension systems, including the seat vertical acceleration response, the seat suspension dynamic travel and so on. For academic purposes and the practical engineering problem, it may be useful to introduce the complex problem in a simplified form.

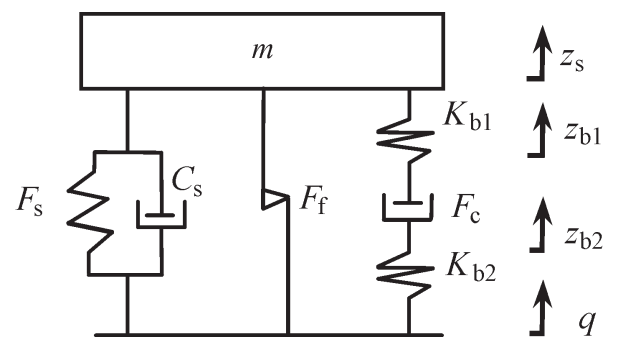

Fig. 2. The vertical dynamic model of the seat system

The motion equations of the model can be written as:

$$
\left\{\begin{array}{l}
m \ddot{z}_{\mathrm{s}}=-F_{\mathrm{s}}-C_{\mathrm{s}}\left(\dot{z}_{\mathrm{s}}-\dot{q}\right)-K_{\mathrm{b} 1}\left(z_{\mathrm{s}}-z_{\mathrm{b} 1}\right)-F_{\mathrm{f}} \\
F_{\mathrm{c}}-K_{\mathrm{b} 1}\left(z_{\mathrm{s}}-z_{\mathrm{b} 1}\right)=0 \\
F_{\mathrm{c}}-K_{\mathrm{b} 2}\left(z_{\mathrm{b} 2}-q\right)=0
\end{array} .\right.
$$

In Eq. (1), the force $F_{\mathrm{f}}$ can be written as: 


$$
F_{\mathrm{f}}=F_{0} \cdot \operatorname{sgn}\left(\dot{z}_{\mathrm{s}}-\dot{q}\right),
$$

where, $F_{0}$ is the magnitude of Coulomb friction force.

The damping force $F_{\mathrm{c}}$ can be written as:

$$
F_{\mathrm{c}}=\left\{\begin{array}{ll}
C_{1}\left(\dot{z}_{\mathrm{b} 1}-\dot{z}_{\mathrm{b} 2}\right) & \dot{z}_{\mathrm{b} 1}-\dot{z}_{\mathrm{b} 2} \geq 0 \\
C_{2}\left(\dot{z}_{\mathrm{b} 1}-\dot{z}_{\mathrm{b} 2}\right) & \dot{z}_{\mathrm{b} 1}-\dot{z}_{\mathrm{b} 2} \leq 0
\end{array},\right.
$$

where, $C_{1}$ is the rebound damping and $C_{2}$ is the compression damping.

The polynomial model was adopted to depict the dynamic properties of the rubber spring [25]; thus, the $F_{\mathrm{s}}$ can be simplified as:

$$
F_{\mathrm{s}}=K_{\mathrm{s} 1}\left(z_{\mathrm{s}}-q\right)+K_{\mathrm{s} 3}\left(z_{\mathrm{s}}-q\right)^{3},
$$

where, $K_{\mathrm{s} 1}$ and $K_{\mathrm{s} 3}$ are the stiffness coefficients.

\section{PARAMETERS IDENTIFICATION}

\subsection{Field Measurements}

To provide accurate input signals for parameters identification, the field measurements were carried out. The driver's weight is $65 \mathrm{~kg}$. For a truck in this study, its drive type is $4 \times 2$, and its gross vehicle weight and load capacity are 5 and 10 tonnes, respectively. Taking the truck with this new-type seat as a test object, an accelerometer (sensor type, Lance LC0173) was installed on the driver's seat base. With the truck under fully laden conditions, on the highway at 65 $\mathrm{km} / \mathrm{h}, 75 \mathrm{~km} / \mathrm{h}$, and $85 \mathrm{~km} / \mathrm{h}$, and on the gravel road at $40 \mathrm{~km} / \mathrm{h}, 50 \mathrm{~km} / \mathrm{h}$, and $60 \mathrm{~km} / \mathrm{h}$, the acceleration signals were tested. Both the highway and the gravel road are relatively straight, and their surfaces are very dry. For each test condition, the sampling length was $40 \mathrm{~s}$, and the sampling frequency was $200 \mathrm{~Hz}$.

To avoid the dynamic characteristic influences of the seat cushion and the driver, further laboratory measurements were undertaken. The seat cushion was removed, and then the seat was secured to the test rig made by Moog Inc. with the driver replaced by a $65-\mathrm{kg}$ matching block. Accelerometers (sensor type, Lance LC0173) were installed on the seat base and on the seat pan. The equipment exerted the previous acceleration excitations for $40 \mathrm{~s}$ from the field measurements, and the accelerations on the seat pan were measured under the driving conditions on the highway and the gravel road. For each laboratory measurement, the sampling length was $40 \mathrm{~s}$, and the sampling frequency was $200 \mathrm{~Hz}$.

\subsection{Model Parameter Identification}

Taking the minimum of quadratic error function $J_{\mathrm{I}}$ between the simulated seat vertical acceleration rootmean-square $\mathrm{RMS}_{\text {sim }}$ and the tested $\mathrm{RMS}_{\text {test }}$, the objective function $J_{\text {I }}$ of parameters identification can be expressed as:

$$
\min \left\{J_{\mathrm{I}}\right\}=\min \left\{\mathrm{RMS}_{\text {sim }}-\mathrm{RMS}_{\text {test }}\right\}^{2},
$$

where, $K_{\mathrm{s} 1}, K_{\mathrm{s} 3}, K_{\mathrm{b} 1}, K_{\mathrm{b} 2}, C_{\mathrm{s}}, C_{1}, C_{2}$, and $F_{0}$ are the variables to be identified.

The vector of the variables to be identified:

$$
\mathbf{x}=\left[K_{\mathrm{s} 1}, K_{\mathrm{s} 3}, K_{\mathrm{b} 1}, K_{\mathrm{b} 2}, C_{\mathrm{s}}, C_{1}, C_{2}, F_{0}\right] .
$$

In order to facilitate the parameters identification, Table 1 provides a list of the variables to be identified.

Table 1. Estimated initial, upper and lower limits values for model parameters identification

\begin{tabular}{llccc}
\hline \multicolumn{2}{l}{ Variables } & Initial values & Lower bound & Upper bound \\
\hline$K_{\mathrm{s} 1}$ & {$[\mathrm{kN} / \mathrm{m}]$} & 12 & 8 & 30 \\
\hline$K_{\mathrm{s} 3}$ & {$\left[\mathrm{kN} / \mathrm{m}^{3}\right]$} & 2120 & 1800 & 9950 \\
\hline$K_{\mathrm{b} 1}$ & {$[\mathrm{kN} / \mathrm{m}]$} & 100 & 80 & 150 \\
\hline$K_{\mathrm{b} 2}$ & {$[\mathrm{kN} / \mathrm{m}]$} & 100 & 80 & 150 \\
\hline$C_{\mathrm{s}}$ & {$[\mathrm{N} \cdot \mathrm{s} / \mathrm{m}]$} & 80 & 100 & 500 \\
\hline$C_{1}$ & {$[\mathrm{~N} \cdot \mathrm{s} / \mathrm{m}]$} & 600 & 300 & 1600 \\
\hline$C_{2}$ & {$[\mathrm{~N} \cdot \mathrm{s} / \mathrm{m}]$} & 200 & 100 & 1000 \\
\hline$F_{0}$ & {$[\mathrm{~N}]$} & 10 & 2 & 30 \\
\hline
\end{tabular}

Based on the target function $J_{\mathrm{I}}$ and the constraint conditions above, the identification problem is a minimal design problem with constraint conditions. This study adopts multi-island genetic algorithm to solve the problem, and the specific identification program was compiled using the software Matlab. This algorithm is a conventional global optimization method [26]. The essential parameters of the algorithm are considered, as listed in Table 2. Based on the built model of the seat system, a MATLAB/Simulink simulation model was created, and the flow chart of parameter identification is shown in Fig. 3.

Based on the signals measured under the driving condition on the highway at $65 \mathrm{~km} / \mathrm{h}, 75 \mathrm{~km} / \mathrm{h}$, and $85 \mathrm{~km} / \mathrm{h}$, the model parameters were identified, respectively. The convergence values of the target function $J_{\mathrm{I}}$ are $0.000012,0.000008$, and 0.000004 , respectively. The results are listed in Table 3 . In order to reduce the error of the identified parameters, the average values at different speeds are regarded as the final results. 
Table 2. The essential parameters of the algorithm

\begin{tabular}{lc}
\hline Parameters & value \\
\hline Sub-population size & 10 \\
\hline Number of islands & 10 \\
\hline Number of generations & 10 \\
\hline Rate of crossover & 1.0 \\
\hline Rate of mutation & 0.01 \\
\hline Rate of migration & 0.01 \\
\hline Interval of migration & 5 \\
\hline Elite size & 1 \\
\hline Tournament size & 0.5 \\
\hline Penalty base & 0.0 \\
\hline Penalty multiplier & 1000.0 \\
\hline Penalty exponent & 2 \\
\hline
\end{tabular}

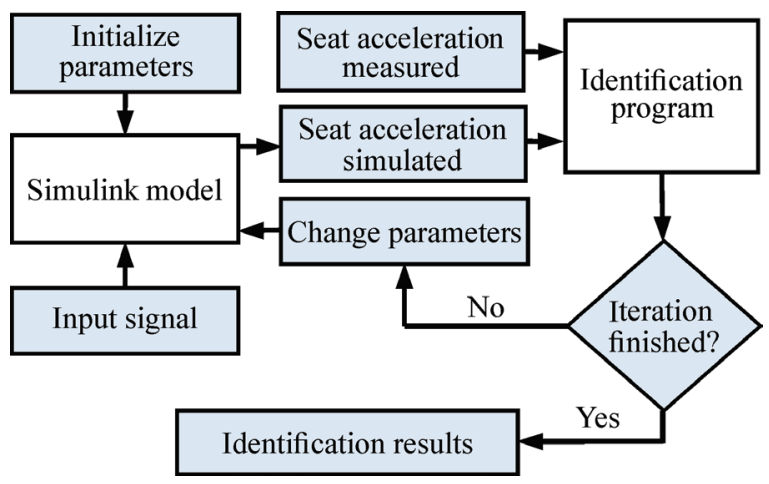

Fig. 3. The flow chart of parameter identification

Table 3. The results of system parameter identification

\begin{tabular}{lccccc}
\hline \multirow{2}{*}{$\begin{array}{c}\text { Mechanical } \\
\text { parameter }\end{array}$} & \multicolumn{3}{c}{ Running Speed $[\mathrm{km} / \mathrm{h}]$} & \multirow{2}{*}{$\begin{array}{c}\text { Average } \\
\text { value }\end{array}$} \\
\cline { 3 - 5 }$K_{\mathrm{s} 1}$ & {$[\mathrm{kN} / \mathrm{m}]$} & 17.1 & 17.5 & 17.3 & 17.3 \\
\hline$K_{\mathrm{s} 3}$ & {$\left[\mathrm{kN} / \mathrm{m}^{2}\right]$} & 9354.8 & 9359.2 & 9351.6 & 9355.2 \\
\hline$K_{\mathrm{b} 1}$ & {$[\mathrm{kN} / \mathrm{m}]$} & 119.3 & 120.4 & 118.6 & 119.4 \\
\hline$K_{\mathrm{b} 2}$ & {$[\mathrm{kN} / \mathrm{m}]$} & 116.8 & 119.5 & 119.3 & 118.5 \\
\hline$C_{\mathrm{s}}$ & {$[\mathrm{N} \cdot \mathrm{s} / \mathrm{m}]$} & 104.2 & 101.1 & 102.7 & 102.7 \\
\hline$C_{1}$ & {$[\mathrm{~N} \cdot \mathrm{s} / \mathrm{m}]$} & 651.7 & 656.3 & 652.8 & 653.6 \\
\hline$C_{2}$ & {$[\mathrm{~N} \cdot \mathrm{s} / \mathrm{m}]$} & 431.5 & 427.8 & 429.3 & 429.5 \\
\hline$F_{0}$ & {$[\mathrm{~N}]$} & 13.9 & 11.2 & 13.2 & 12.8 \\
\hline & & & & &
\end{tabular}

\subsection{Simulation Validation of the Identified Parameters}

To verify the correctness of the parameters identified, a finite element method (FEM) analysis about the compression-spring force of the rubber has been made. This study adopts well known Moony-Rivlin model to simulate mechanical properties of rubber spring in ANSYS software [27]. A comparison between deformation curve of the rubber spring calculated by
ANSYS software and that identified is shown in Fig. 4.

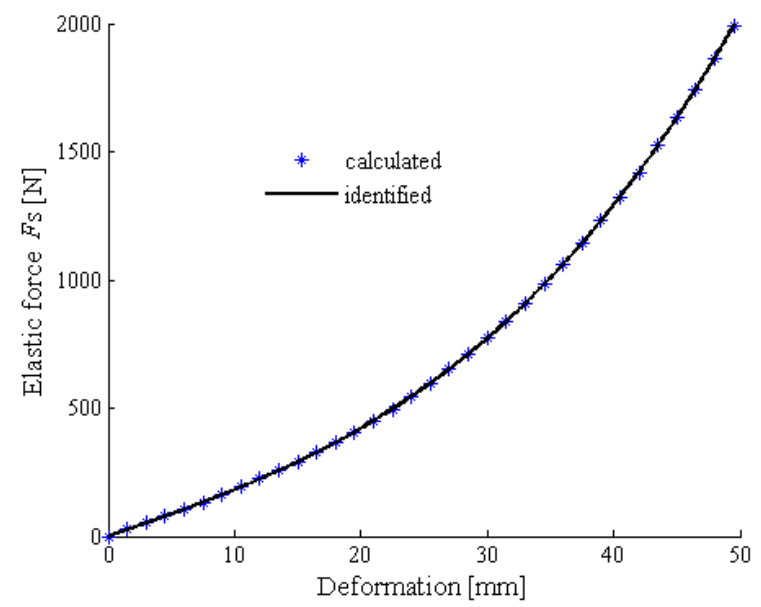

Fig. 4. A comparison between the deformation curve calculated by ANSYS software and that identified

From Fig. 4, it can be known that the deformation curve calculated by ANSYS software is extremely close to that identified. The results show that the deformation curve identified is acceptable. To further verify the effectiveness of the seat suspension system model with the parameters identified, using the signals measured under the driving condition on the gravel road at $40 \mathrm{~km} / \mathrm{h}, 50 \mathrm{~km} / \mathrm{h}$, and $60 \mathrm{~km} / \mathrm{h}$, the simulations were conducted, respectively. The signal length for each simulation is $15 \mathrm{~s}$. A comparison of the seat vertical acceleration RMS values between the simulated and those measured on the gravel road is shown in Table 4.

Table 4. Comparison of the seat vertical acceleration RMS values between the simulated and the measured

\begin{tabular}{lcccc}
\hline \multirow{2}{*}{ RMS } & & \multicolumn{3}{c}{ Running Speed $[\mathrm{km} / \mathrm{h}]$} \\
\cline { 3 - 5 } & & 40 & 50 & 60 \\
\hline Measured & {$\left[\mathrm{m} / \mathrm{s}^{2}\right]$} & 1.87 & 2.26 & 2.75 \\
\hline Simulated & {$\left[\mathrm{m} / \mathrm{s}^{2}\right]$} & 1.76 & 2.14 & 2.96 \\
\hline Absolute deviation & {$\left[\mathrm{m} / \mathrm{s}^{2}\right]$} & -0.11 & -0.12 & 0.21 \\
\hline Relative deviation & {$[\%]$} & -5.88 & -5.31 & 7.64 \\
\hline
\end{tabular}

From Table 4, the relative deviations of the seat vertical acceleration RMS values between the simulated and the measured are $-5.88 \%,-5.31 \%$, and $7.64 \%$, respectively. The results show that the model with the identified parameters is workable. In order to further compare the discrepancies between the simulated and the measured, Fig. 5 presents a comparison of the seat vertical acceleration responses $a_{\mathrm{z}}$ between the simulated and measured at $60 \mathrm{~km} / \mathrm{h}$. 
Fig. 6 presents a comparison of the seat vertical acceleration power spectral density (PSD) between the simulated and measured at $60 \mathrm{~km} / \mathrm{h}$. From Figs. 5 and 6 , both the simulated $a_{\mathrm{z}}$ and PSD coincide well with the measured, respectively. The results show that the model with the parameters identified is workable.

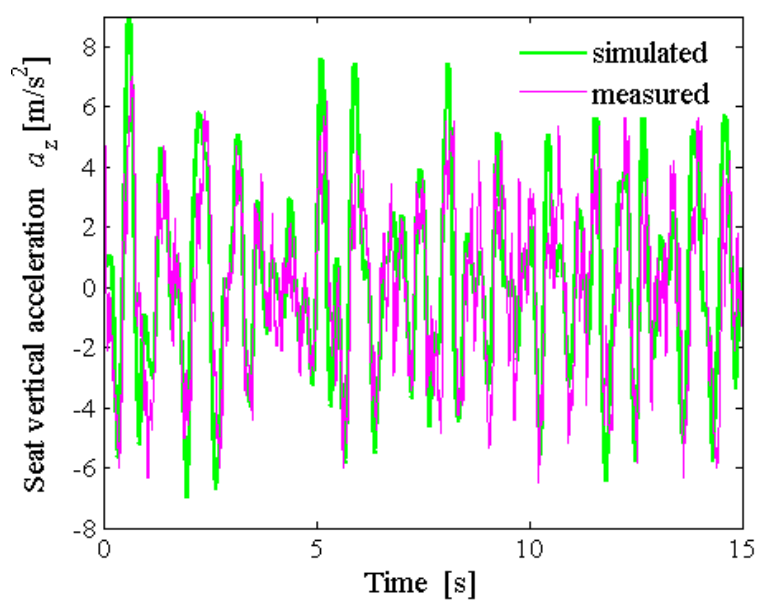

Fig. 5. Comparison of the seat vertical acceleration response az between the simulated and the measured

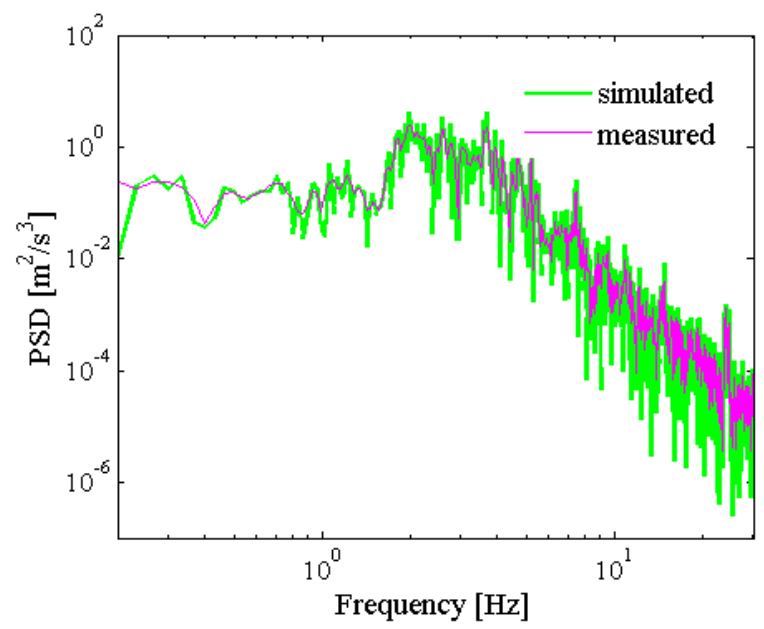

Fig. 6. Comparison of the seat vertical acceleration PSD between the simulated and the measured

\section{SENSITIVITY ANALYSIS AND DAMPING MATCH}

\subsection{Sensitivity Analysis of the Model Parameters}

At present, the commonly used index of ride comfort is weighted RMS acceleration recommended by ISO 2631-1:1997 [28]. According to this standard, the weighted RMS acceleration at seat pan and seat back in three directions should be calculated for evaluating ride comfort. The seat vertical frequency-weighted
RMS acceleration was adopted to evaluate ride comfort in this study. The seat vertical frequencyweighted RMS acceleration $\sigma_{\ddot{z}_{\mathrm{s}}}$ can be expressed as:

$$
\sigma_{\ddot{z}_{\mathrm{s}}}=\left[\int_{0.5}^{80} w^{2}(f) G_{a}(f) \mathrm{d} f\right]^{1 / 2},
$$

where, $G_{a}(f)$ is the power spectral density of the seat's vertical acceleration. The frequency weighted coefficient $w(f)$ in Eq. (7) is as follows:

$$
w(f)=\left\{\begin{array}{ll}
0.5 & (0.5 \leq f<2.0) \\
f / 4.0 & (2.0 \leq f<4.0) \\
1.0 & (4.0 \leq f<12.5) \\
12.5 / f & (12.5 \leq f<80.0)
\end{array} .\right.
$$

In this section, the sensitivity analysis was done to reveal the effects of the model parameters on the index of ride comfort. According to [29], in this paper, the sensitivity can be defined as:

$$
\begin{gathered}
S_{ \pm 10 \%}=\left[\frac{\sigma_{\ddot{z}_{\mathrm{s}}}(B \pm 10 \% \cdot B)-\sigma_{\ddot{z}_{\mathrm{s}}}(B)}{\sigma_{\ddot{z}_{\mathrm{s}}}(B)}\right] /[ \pm 10 \%] . \\
S=\sqrt{\frac{1}{2}\left(\left|S_{+10 \%}\right|+\left|S_{-10 \%}\right|\right)}
\end{gathered}
$$

where, $B$ is the design variable, including $K_{\mathrm{s} 1}$, $K_{\mathrm{s} 3}, K_{\mathrm{b} 1}, K_{\mathrm{b} 2}, C_{\mathrm{s}}, C_{1}, C_{2}$, and $F_{0} ; S_{ \pm 10 \%}$ is the level of sensitivity in the given design range $\pm 10 \% ; S$ is the sensitivity.

The calculated sensitivities of the model parameters under different conditions are shown in Table 5. The final sensitivity order of model parameters is shown in Fig. 7.

Table 5. The calculated sensitivities of the model parameters under different conditions

\begin{tabular}{cccccccc}
\hline $\begin{array}{c}\text { Mech. } \\
\text { par. }\end{array}$ & On the gravel road $[\mathrm{km} / \mathrm{h}]$ & \multicolumn{3}{c}{ On the highway $[\mathrm{km} / \mathrm{h}]$} & Average \\
\cline { 2 - 7 } & 40 & 50 & 60 & 65 & 75 & 85 & value \\
\hline$K_{\mathrm{s} 1}$ & 0.412 & 0.408 & 0.410 & 0.413 & 0.410 & 0.411 & 0.411 \\
\hline$K_{\mathrm{s} 3}$ & 0.232 & 0.231 & 0.234 & 0.230 & 0.233 & 0.231 & 0.232 \\
\hline$K_{\mathrm{b} 1}$ & 0.182 & 0.189 & 0.186 & 0.187 & 0.185 & 0.184 & 0.186 \\
\hline$K_{\mathrm{b} 2}$ & 0.187 & 0.185 & 0.181 & 0.182 & 0.189 & 0.186 & 0.185 \\
\hline$C_{\mathrm{s}}$ & 0.112 & 0.111 & 0.110 & 0.112 & 0.113 & 0.112 & 0.112 \\
\hline$C_{1}$ & 0.321 & 0.322 & 0.329 & 0.324 & 0.322 & 0.326 & 0.324 \\
\hline$C_{2}$ & 0.281 & 0.280 & 0.281 & 0.279 & 0.283 & 0.282 & 0.281 \\
\hline$F_{0}$ & 0.090 & 0.091 & 0.089 & 0.093 & 0.091 & 0.092 & 0.091 \\
\hline
\end{tabular}

Table 5 shows almost the same sensitivity distribution of the model parameters under different conditions. The average value of the sensitivities was taken as the real sensitivity. From Fig. 7, the 
linear stiffness coefficient $K_{\mathrm{s} 1}$ of the spring has the most substantial effect on the seat vertical frequencyweighted RMS acceleration, and followed by the equivalent damping coefficients $C_{1}$ and $C_{2}$ of rebound stroke compression and stroke. For the magnitude of Coulomb friction force $F_{0}$, its performance impact is minimal; however, it cannot be ignored for the dynamic model built. In addition, all the sensitivities are less than 0.45 , which shows the identification values of model parameters are highly stable. That is to say, even though a deviation exists for each identified parameter of the model, the dynamic response does not change dramatically.

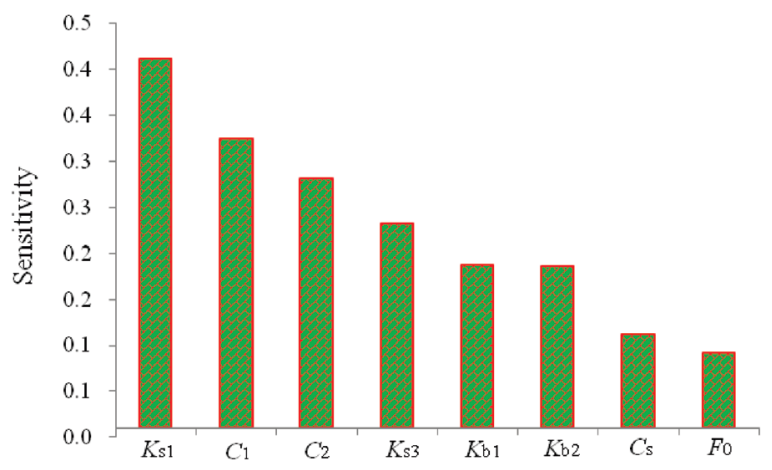

Fig. 7. The sensitivity order of model parameters

\subsection{Damping Match}

From the sensitivity analysis above, for the given rubber spring, the equivalent damping coefficients $C_{1}$ and $C_{2}$ have a critical influence on ride comfort. Thus, in this section, the damping match for the seat suspension system will be carried out.

To reduce the vibration from the seat base, the damping match objective function $J_{0}$ can be expressed as:

$$
\min \left\{J_{\mathrm{o}}\right\}=\min \left\{\sigma_{\ddot{z}_{\mathrm{s}}}\right\},
$$

where, $C_{1}$ and $C_{2}$ are the variables to be optimized.

In the optimization process, to ensure that the collision probability between the seat frame and the bump stop is within $0.135 \%$, the ratio of the standard deviation $\sigma\left(f_{\mathrm{d}}\right)$ of the seat suspension dynamic travel $f_{\mathrm{d}}$ to the limited travel $\left[f_{\mathrm{d}}\right]$ of the seat suspension system must satisfy:

$$
\frac{\sigma\left(f_{\mathrm{d}}\right)}{\left[f_{\mathrm{d}}\right]} \leq \frac{1}{3}
$$

where, the dynamic limited travel $\left[f_{\mathrm{d}}\right]$ of the seat suspension for the original truck is $35 \mathrm{~mm}$.
According to the study on the design of seat suspension [30], the optimization range of the damper damping coefficients for the seat suspension must satisfy:

$$
\left\{\begin{array}{l}
500 \leq C_{1} \leq 1100 \\
100 \leq C_{2} \leq 600
\end{array},\right.
$$

Based on the target function $J_{\mathrm{o}}$ and the constraint conditions above, the optimization problem is also a minimal design problem with constraint conditions. This study also adopts a multi-island genetic algorithm to solve the problem, and the damping optimization program was compiled. The essential parameters of the algorithm are the same as those of the identification program. The flow chart of damping optimization is shown in Fig. 8.

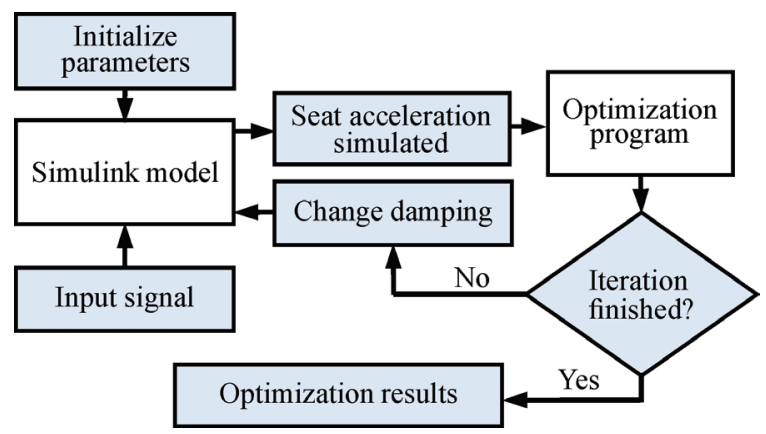

Fig. 8. The flow chart of damping optimization

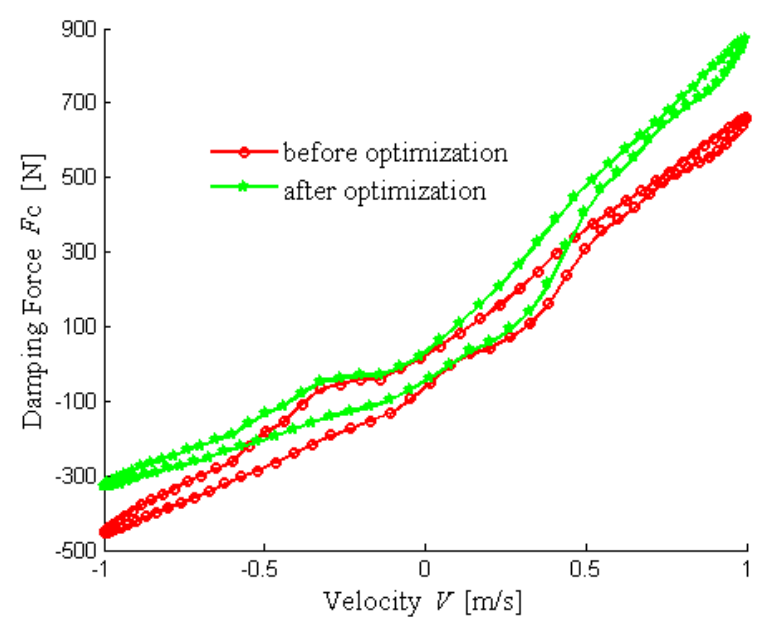

Fig. 9. The curve of velocity vs. damping force

Using the signals measured under the driving condition on the highway at $85 \mathrm{~km} / \mathrm{h}$ that the truck travels most, the damping coefficients $C_{1}$ and $C_{2}$ of the damper were optimized, which are 891.8 and $329.5 \mathrm{~N} \cdot \mathrm{s} / \mathrm{m}$, respectively. The ratios of the rebound damping coefficient $C_{1}$ to the rebound damping coefficient $C_{2}$ for before and after optimization are 
1.52 and 2.71 , respectively. Base on the requirement of the damping coefficients optimized, the damper was redesigned by the damper manufacturer through trial and error. A comparison of the damper damping characteristics curve measured between before and after optimization is shown in Fig. 9.

From Fig. 9, after optimization, the rebound damping force becomes larger, while the compression damping force becomes smaller. Thus, both the damping coefficients and the ratio of the rebound damping coefficient $C_{1}$ to the rebound damping coefficient $C_{2}$ have significant influences on ride comfort.

\section{TEST VERIFICATION}

To verify the effectiveness of the damping coefficients optimized, a bench test was conducted.

The test was conducted on the test rig. The seat system with the damper damping coefficients optimized was attached to the test rig. The accelerometer was installed on the seat pan, and the driver was replaced with $65 \mathrm{~kg}$ sandbags. The sandbags were restrained with a belt. The equipment exerted the previous acceleration excitations mentioned above from the field measurements, and the accelerations on the seat pan were measured under the driving conditions on the highway at $65 \mathrm{~km} / \mathrm{h}$, $75 \mathrm{~km} / \mathrm{h}$, and $85 \mathrm{~km} / \mathrm{h}$, and on the gravel road at 40 $\mathrm{km} / \mathrm{h}, 50 \mathrm{~km} / \mathrm{h}$, and $60 \mathrm{~km} / \mathrm{h}$. For each test condition, accelerations were collected for $40 \mathrm{~s}$, filtered with minimum cut-off $0.5 \mathrm{~Hz}$ and maximum cut-off 80 $\mathrm{Hz}$, and digitized at 1024 samples/s. According to Eq. (7), the seat vertical frequency-weighted RMS accelerations for different conditions were calculated. The results and comparisons between before and after optimization are shown in Table 6.

Table 6. Comparison of the seat vertical frequency-weighed RMS acceleration before and after optimization

\begin{tabular}{ccccc}
\hline \multirow{2}{*}{$\begin{array}{c}\text { Driving } \\
\text { condition }\end{array}$} & \multicolumn{3}{c}{ RMS acceleration } \\
\cline { 2 - 5 } & $\begin{array}{c}\text { Before } \\
\text { optimization } \\
{\left[\mathrm{m} / \mathrm{s}^{2}\right]}\end{array}$ & $\begin{array}{c}\text { After } \\
\text { optimization } \\
{\left[\mathrm{m} / \mathrm{s}^{2}\right]}\end{array}$ & $\begin{array}{c}\text { Relative } \\
\text { deviation } \\
{[\%]}\end{array}$ \\
\hline \multirow{2}{*}{$\begin{array}{c}\text { Gravel } \\
\text { road }\end{array}$} & $40[\mathrm{~km} / \mathrm{h}]$ & 1.71 & 1.52 & 11.1 \\
\cline { 2 - 5 } & $50[\mathrm{~km} / \mathrm{h}]$ & 1.97 & 1.80 & 8.6 \\
\hline \multirow{3}{*}{ Highway } & $60[\mathrm{~km} / \mathrm{h}]$ & 2.03 & 1.86 & 8.4 \\
\cline { 2 - 5 } & $65[\mathrm{~km} / \mathrm{h}]$ & 0.51 & 0.45 & 11.8 \\
\cline { 2 - 5 } & $75[\mathrm{~km} / \mathrm{h}]$ & 0.56 & 0.50 & 12.0 \\
\hline
\end{tabular}

From Table 6, it can be seen that, under the driving condition on the highway at $65 \mathrm{~km} / \mathrm{h}, 75 \mathrm{~km} / \mathrm{h}$, and $85 \mathrm{~km} / \mathrm{h}$, the seat vertical frequency-weighted RMS acceleration values are decreased by $11.8 \%$, $12 \%$, and $10.2 \%$, respectively. Under the driving condition on the gravel road at $40 \mathrm{~km} / \mathrm{h}, 50 \mathrm{~km} / \mathrm{h}$, and $60 \mathrm{~km} / \mathrm{h}$, the seat vertical frequency-weighted RMS acceleration values are decreased by $11.1 \%, 8.6 \%$, and $8.4 \%$, respectively. On the whole, the index of ride comfort has an improvement of about $10 \%$.

In addition, the test for each running condition above was also conducted with the driver sitting on the seat. During testing, the driver sat upright with his back in contact with the seat back, placed his hands in his laps, and was restrained by a seat belt. In comparison, the driver would consider the ride comfort better than before optimization.

The results show that the seat system model and the damping match method proposed are reliable, and the damping coefficients matched are workable and effective.

\section{CONCLUSIONS}

A new mathematical model was built to better describe the novel nonlinear suspension for seat system, which can capture the main dynamic properties of seat suspension system. Using the signals measured under the driving condition on the highway at different running speeds, the model parameters were identified. Using the signals measured under the driving condition on the gravel road at different running speeds, the model was verified, and the results show that the parameters identified are workable. From the sensitivity analysis, the linear stiffness coefficient $K_{\mathrm{s} 1}$ of the spring has the most substantial effect on the seat vertical frequency-weighted RMS acceleration, followed by the equivalent damping coefficients $C_{1}$ and $C_{2}$ of rebound stroke compression and stroke. For the magnitude of Coulomb friction force $F_{0}$, its performance impact is minimal.

Using the signals measured under the driving condition on the highway that the truck travels on most, the damper damping coefficients $C_{1}$ and $C_{2}$ were optimized. The results optimized show that both the damping coefficients and the ratio of the rebound damping coefficient $C_{1}$ to the rebound damping coefficient $C_{2}$ have significant influences on ride comfort. The bench test results further show that the seat system model and the damping match method proposed are reliable, and the damping coefficients matched are workable and effective. The novel nonlinear suspension and the method of the damping coefficients tuning provide a valuable reference for 
further improving ride comfort to protect the driver's health better.

In the following study, the more complex model for the new type of suspension system will be researched, and the simulations with a complete vehicle including an appropriate model of the seat and the human body will be conducted. The random input running test and pulse input running test for ride comfort with the vehicle will be carried out according to the standard ISO2631-1:1997.

\section{ACKNOWLEDGEMENTS}

This work is supported by the National Natural Science Foundation of China (51575325), the Nature Science Foundation of Shandong (ZR2013EEM007), and Key R \& D projects in Shandong Province (2015GGX105006).

\section{REFERENCES}

[1] Park, S.J., Lee, Y.S., Nahm, Y.E., Lee, J.W., Kim, J.S. (1998). Seating physical characteristics and subjective comfort: design considerations. SAE Technical Paper, no. 980653, DOI:10.4271/980653.

[2] Demontis, S., Giacoletto, M. (2002). Prediction of car seat comfort from human-seat interface pressure distribution. SAE Technical Paper, no. 2002-01-0781, D0I:10.4271/2002-010781.

[3] Blood, R.P., Ploger, J.D., Yost, M.G., Ching, R.P., Johnson, P.W. (2010) Whole body vibration exposures in metropolitan bus drivers: A comparison of three seats. Journal of Sound and Vibration, vol. 329, no. 1, p. 109-120, D0l:10.1016/j. jsv.2009.08.030.

[4] Kim, H.J., Martin, B.J. (2013). Biodynamic characteristics of upper limb reaching movements of the seated human under whole-body vibration. Journal of Biomechanical Engineering, vol. 29, no. 1, p. 12-22, D0l:10.1123/jab.29.1.12.

[5] Baig, H.A., Dorman, D.B., Bulka, B.A., Shivers, B.L., Chancey, V.C., Winkelstein, B.A. (2014). Characterization of the frequency and muscle responses of the lumbar and thoracic spines of seated volunteers during sinusoidal whole driver vibration. Journal of Biomechanical Engineering, vol. 136, no. 10, p. 1-7, DOI:10.1115/1.4027998.

[6] Griffin, M.J. (2012). Frequency-dependence of psychophysical and physiological responses to hand-transmitted vibration. Industrial Health, vol. 50, no. 5, p. 354-369, Dol:10.2486/ indhealth.MS1379.

[7] Eger, T.R., Contratto, M.S., Dickey, J.P. (2013). Influence of driving speed, terrain, seat performance and ride control on predicted health risk based on ISO 2631-1 and EU Directive 2002/44/EC. Journal of Low Frequency Noise, Vibration and Active Control, vol. 30, no. 4, p. 291-312, D0l:10.1260/02630923.30.4.291.

[8] Luo, R.K., Cook, P.W., Wu, W.X., Mortel, W.J. (2003). Fatigue design of rubber springs used in rail vehicle suspensions.
Proceedings of the Institution of Mechanical Engineers Part F Journal of Rail and Rapid Transit, vol. 217, no. 3, p. 237-240, DOl:10.1243/095440903769012920.

[9] Luo, R.K. (2015). Creep modelling and unloading evaluation of the rubber suspensions of rail vehicles. Proceedings of the Institution of Mechanical Engineers Part F Journal of Rail and Rapid Transit, vol. 230, no. 4, p. 1077-1087, DOI:10.1177/0954409715576260.

[10] Sebesan, I., Zaharia, N.L., Spiroiu, M.A., Fainus, L. (2015). Rubber suspension, a solution of the future for railway vehicles. Materiale Plastice, vol. 52, no. 1, p. 93-96.

[11] Pang, H., Li, H.Y., Fang, Z.D., Zhu, X.Y. (2012). Finite element analysis of mechanical characteristics on the composite rubber suspension of heavy vehicle. Applied Mechanics and Materials, vol. 121-126, p. 1702-1706, D0l:10.4028/www. scientific.net/AMM.121-126.1702.

[12] Thaijaroen, W., Harrison, A.J.L. (2010). Nonlinear dynamic modelling of rubber isolators using six parameters based on parabolic spring, springpot, and smooth-slip friction element. Polymer Testing, vol. 29, no. 7, p. 857-865, D0l:10.1016/j. polymertesting.2010.07.007.

[13] Sun, D.W., Chen, Z.G., Zhang, G.Y., Eberhard, P. (2011). Modeling and parameter identification of amplitude- and frequency-dependent rubber isolator. Journal of Central South University of Technology, vol. 18, p. 672-678, D0l:10.1016/j. polymertesting.2010.07.007.

[14] Sun, D.W., Eberhard, P., Zhang, G.Y., (2011). Parameter identification of rubber isolators using frequency-dependent spring and damper coefficients. Journal of Donghua University, vol. 28, no. 2 p. 134-138.

[15] Ren, L.Z., Liu, L., Ren, Z.C. (2012). Centrifuge rubber suspension spring characteristics of the experimental research, Applied Mechanics \& Materials, vol. 157-158, p. 563-566, D0I:10.4028/www.scientific.net/AMM.157-158.563.

[16] Zhou, C.F., Sun, B.B., Chen, N., Zhang, X.Y., Sun, Q.H. (2007). Parameters identification and optimal design of vehicle seat suspension system. Transactions of the Chinese Society for Agricultural Machinery, vol. 38, p. 24-27. (in Chinese)

[17] Donati, P. (2002). Survey of technical preventative measures to reduce whole-driver vibration effects when designing mobile machinery. Journal of Sound and Vibration, vol. 253, no. 1, p. 169-183, DOI:10.1006/jsvi.2001.4254.

[18] Gohari, M., Tahmasebi, M. (2014). Off-road vehicle seat suspension optimisation, Part II: Comparative study between meta-heuristic optimisation algorithms. Journal of Low Frequency Noise, Vibration and Active Control, vol. 33, no. 4, p. 443-454, DOl:10.1260/0263-0923.33.4.443.

[19] Krishnasamy, D.P., Jayaraj, J,. John, D. (2013). Experimental investigation on road vehicle active suspension. Strojniški vestnik - Journal of Mechanical Engineering, vol. 59, no. 10, p. 620-625, D0I:10.5545/sv-jme.2012.925.

[20] Griffin, M. (1990). Handbook of Human Vibrations. Academic Press, London.

[21] Rakheja, S., Afework, Y., Sankar, S. (1994). An analytical and experimental investigation of the driver-seat-suspension system. Vehicle System Dynamic, vol. 23, no. 1, p. 501-524, DOI:10.1080/00423119408969072. 
[22] Berg, M. (1998). A nonlinear rubber spring model for vehicle dynamics analysis. Vehicle System Dynamics, vol. 29, no. supl.1, p. 723-728, D0l:10.1080/00423119808969599.

[23] Shi, H.L., Wu, P.B. (2015). A nonlinear rubber spring model containing fractional derivatives for use in railroad vehicle dynamic analysis. Proceedings of the Institution of Mechanical Engineers, Part F: Journal of Rail and Rapid Transit, vol. 230, no. 7, p. 1745-1759, Dol:10.1177/0954409715614871.

[24] Silveira, M-, Pontes, J.B.R., Balthazar, J.M. (2014). Use of nonlinear asymmetrical shock absorber to improve comfort on passenger vehicles. Journal of Sound and Vibration, vol. 333, no. 7, p. 2114-2129, D0l:10.1016/j.jsv.2013.12.001.

[25] Stein, G.J., Múčka, P., Gunston, T.P. (2009). A study of locomotive driver's seat vertical suspension system with adjustable damper. Vehicle System Dynamics, vol. 47, no. 3, p. 363-386, DOI:10.1080/00423110802148920.

[26] Hu, X.Z., Chen, X.Q., Zhao, Y., Yao, W. (2014). Optimization design of satellite separation systems based on multi-island genetic algorithm. Advances in Space Research, vol. 53, no. 5, p. 870-876, D0I:10.1016/J.asr.2013.12.021.

[27] Arruda, E.M., Boyce, M.C. (1993). A three-dimensional constitutive model for the large stretch behavior of rubber elastic material. Journal of the Mechanics \& Physics of Solids, vol. 41, no. 2, p. 389-412, D0l:10.1016/0022-5096(93)900136.

[28] ISO 2631-1 (1997). Mechanical Vibration and ShockEvaluation of Human Exposure to Whole-Driver VibrationPart 1: General Requirements. International Organization for Standardization, Geneva.

[29] Park, C., Kim, Y., Bae, D. (2009). Sensitivity analysis of suspension characteristics for Korean high speed train. Journal of Mechanical Science and Technology, vol. 23, no. 4, p. 938-941, D0l:10.1007/s12206-009-0316-5.

[30] Zhou, C.C. (2011), Vehicle Suspension Design and Theory. Peking University Press, Beijing, p. 40-42. (in Chinese) 